\title{
Nail mélanoma
}

H. Palamino ${ }^{1 *}$, F.Elgaitibi ${ }^{2}$, M.Meziane ${ }^{3}$, N.Ismaili ${ }^{4}$, L.Benzekri ${ }^{5}$, K. Senouci ${ }^{6}$ Departement of Dermatology-Venerology, Ibn Sina Hospital, Rabat, Morocco. Mohammed V University in Rabat

*Corresponding Author: H. Palamino, Departement of Dermatology-Venerology, Ibn Sina Hospital, Rabat, Morocco. Received date: May 03, 2021; Accepted date: May 14, 2021; Published date: May 17, 2021

Citation: H. Palamino, F.Elgaitibi, M.Meziane, N.Ismaili, L.Benzekri, K. Senouci. (2021) Nail mélanoma. J. Dermatology and Dermatitis. 6(1); Doi: 10.31579/2578-8949/073

Copyright: @2021 H. Palamino, This is an open-access article distributed under the terms of The Creative Commons. Attribution License, which permits unrestricted use, distribution, and reproduction in any medium, provided the original author and source are credited.

\section{Introduction}

Melanoma is originating from melanocytes, it is a malignant tumor with high metastatic potential. It is the leading cause of moratlity from skin cancer, Nail melanoma is a rare form of malignant melanoma. we report a new case of this rare localization [1].

\section{Case report}

A 66-year-old man, chronic smoking, who presented to our department for a nail lesion that has been evolving for more than 5 years, following a trauma.
Dermatological examination revealed an ulcerative lesion, budding, blackish, irregular, measuring more than $2 \mathrm{~cm}$ by $1.5 \mathrm{~cm}$, with destruction of the nail at the level of the right toe and a periungual hyperpigmentation (Fig 1), the The rest of the clinical examination was unremarkable. Faced with this lesion, we first mentioned a nail melanoma and we performed a skin biopsy which confirmed this diagnosis.

Ultrasound of the lymph node areas, chest, abdomen and pelvis, computed tomography, and brain magnetic resonance imaging were normal. An amputation was proposed to the patient.

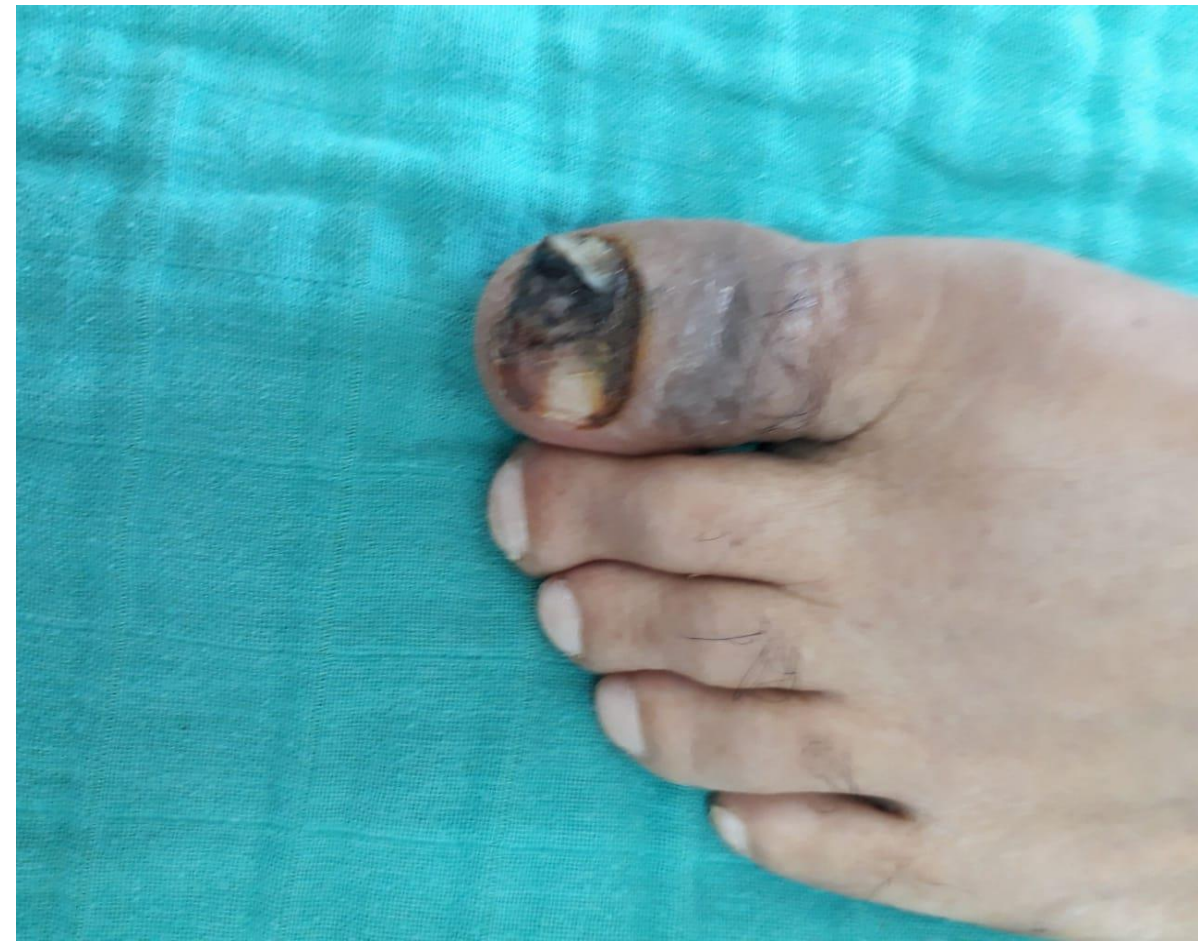

Figure 1 : Hyperpigmented budding ulcerative lesion of the big toe with periungual hyperpigmentation.

\section{Discussion}

We report through this case, a rare anatomical variant of acro-lentiginous melanoma, it represents 1.8 to $8.1 \%$ of melanomas, Clinically, nail melanoma appears in the form of a melanic band, which could be associated Hutchinson's sign (pigmentation of the lateral or proximal nail folds). It can also take on the appearance of an erythematous macule with 
irregular edges [2]. Considering the antecedent of the trauma, the lesion was taken as a subungual hematoma by the patient which was at the origin of the delay of the diagnosis, in the literature, the link between the trauma and the melanoma is suggested, because of the strong preponderance of nail melanoma on the thumb and big toe, which are more prone to trauma [3].

\section{Conclusion:}

We report through this case report a rare form of melanoma, occurring following a trauma, which was the cause of a delay in diagnosis

\section{References}

1. Redondo P, Solano T, Bauza A, Lloret P. (2001) Amelanotic melanoma presenting as a scar. Arch Intern Med.; 161(15):1912-3.

2. Argenziano G, Zalaudek I, Corona R et al. (2004) Vascular structures in skin tumors : a dermoscopy study. Arch Dermatol.; 140(12):1485-9.

3. Mohrle M, Hafner HM. (2002) Is subungual melanoma related to trauma? Dermatology. 204(4):259-261.

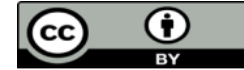

This work is licensed under Creative Commons Attribution 4.0 License

\section{To Submit Your Article Click Here: Submit Manuscript}

DOI: $10.31579 / 2578-8949 / 073$

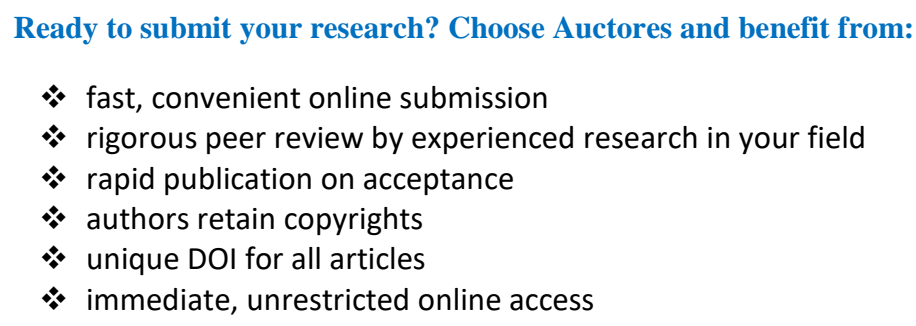

At Auctores, research is always in progress.

Learn more www.auctoresonline.org/journals/dermatology-anddermatitis 